\title{
The Microbiome in Psoriasis and Psoriatic Arthritis: Joints
}

\author{
Jose U. Scher
}

ABSTRACT. The microbiome is a known and established immunomodulator of many inflammatory disorders, including psoriasis and psoriatic arthritis. Microbes co-evolved with their human hosts and provide them with nutritional, metabolic, and immunologic support. An accumulating body of evidence has revealed that psoriatic diseases are characterized by a state of intestinal dysbiosis, which has been linked to a decrease in beneficial commensals and fatty acids. This has been shown in both animal models and human samples, and multiple studies have addressed the physiological and potentially pathogenic role of intestinal and cutaneous microbes in human health and disease. In this review, we discuss state-of-the-art literature in the field of the microbiome in psoriatic diseases that was presented during the Group for Research and Assessment of Psoriasis and Psoriatic Arthritis (GRAPPA) 2017 annual meeting, with a special emphasis on synovio-entheseal inflammation. A better understanding of these microbe-host interactions can lead to novel diagnostic and therapeutic targets. (J Rheumatol Suppl. 2018 June;94:32-5; doi:10.3899/jrheum.180134)

Key Indexing Terms:

PSORIATIC ARTHRITIS

MICROBIOME

GRAPPA
JOINTS

PSORIASIS

SPONDYLOARTHRITIS

For millennia, microbes have co-evolved with their human hosts, populating most mucosal sites. These microorganisms are fundamental to their host's physiology and help maintain immune and metabolic homeostasis. An accumulating body of literature has established the mechanisms that underlie the crosstalk between the microbiome-mucosal interface and the downstream host immune response. However, the precise molecular signaling that directs this microbial influence in disease pathogenesis is emerging and continues to be a central research area in the fields of inflammation, oncology, and autoimmunity.

Joshua Lederberg defined and described the microbiome as "the ecological communities of commensal, symbiotic, and pathogenic microorganisms (including their genes) that

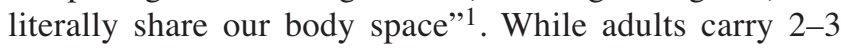

From the Psoriatic Arthritis Center, Division of Rheumatology, New York University Langone Health; Microbiome Center for Rheumatology and Autoimmunity (MiCRA), Division of Rheumatology, New York University School of Medicine and Hospital for Joint Diseases, New York, New York, USA.

As part of the supplement series GRAPPA 2017, this report was reviewed internally and approved by the Guest Editors for integrity, accuracy, and consistency with scientific and ethical standards.

Source of support: Grants No. K23AR064318 and R03AR072182 from the US National Institute of Arthritis and Musculoskeletal and Skin Diseases to Dr. Scher; The Colton Center for Autoimmunity; The Riley Family Foundation; and The Beatriz Snyder Foundation.

J.U. Scher, MD, Psoriatic Arthritis Center, Division of Rheumatology, New York University Langone Health, and MiCRA, Division of Rheumatology, New York University School of Medicine and Hospital for Joint Diseases.

Address correspondence to Dr. J.U. Scher, Division of Rheumatology, New York University Hospital for Joint Diseases, 301 East 17th St., Room 1608, New York, New York 10003, USA. E-mail: Jose.Scher@nyumc.org pounds of bacteria at any given moment, the genes within the human microbiome astoundingly outnumber the host's genetic contribution 100 -fold $^{2}$. These populations, with niche-specific characteristics, inhabit the upper and lower respiratory tract, skin, upper gastrointestinal tract, and female genital tract. However, the largest proportion of human microorganisms resides in the lower gastrointestinal tract, which is home to hundreds of bacterial, viral, and fungal species that form a complex and dynamic ecosystem ${ }^{3}$.

The microbial colonization of the gut begins at birth with vaginal- or cutaneous-derived bacteria, depending on delivery mode ${ }^{4}$. These populations vary significantly, and the intestine's final composition depends on many factors, including host genetics, milk and food types, maternal microbiota, and exposure to antibiotics and other insults 5 .

After the first year of life (when solid food is introduced), the human microbiome begins to maintain its overall structure over time and becomes robust and resilient ${ }^{2,6}$. However, when this equilibrium is perturbed, a dysbiotic process can serve as a triggering factor for the initiation and perpetuation of many inflammatory arthritides, including rheumatoid arthritis (RA), spondyloarthritis (SpA), and psoriatic arthritis (PsA) ${ }^{7}$. This process has been studied and validated over the last 2 decades in animal models of these disorders, where specific perturbations in the microbiome's composition can result in downstream inflammatory events at mucosal surfaces, ultimately leading to systemic disease in susceptible hosts ${ }^{5}$. Multiple cells residing in the intestinal lamina propria appear to be important in translating dysbiosis into local and distal proinflammatory programs, including

Personal non-commercial use only. The Journal of Rheumatology Copyright @ 2018 . All rights reserved. 
dendritic cells, Th17 cells, plasma cells, innate lymphoid cells, $\gamma-\delta$ T cells, and several others ${ }^{8}$. Several mechanisms have been proposed through which microbiome community perturbations may direct the immune response, including altered epithelial and mucosal permeability, loss of immune tolerance to components of commensals, and trafficking of effector immune cells into the synovium.

\section{Intestinal Microbiome in PsA and SpA: From Models to Humans}

The clinical and biological connection between SpA, PsA, and gut inflammation is well established. As a group, SpA-spectrum diseases share a genetic predisposition (i.e., HLA-B27); effector immune cells in their pathogenesis (Th17 cells and other type-17 cells); and clinical manifestations around peripheral and axial arthritis, psoriasis, and intestinal inflammation. The reason certain specific phenotypes are expressed in particular individuals at the expense of other phenotypes has remained one of the leading enigmas in the field. What is more certain is the well-established connection between the development of synovio-entheseal inflammation and psoriasis in the context of clinical (and subclinical) gut inflammation (and vice versa). This is best exemplified by the so-called "enteroarthropathies," in which intestinal infectious agents trigger distal disease.

This is indeed the case in reactive arthritis $(\operatorname{ReA})$, where bacterial gut pathogens cause joint inflammation in genetically predisposed patients 9 . Moreover, about $20 \%$ of patients with ReA go on to develop ankylosing spondylitis (AS). A similar pattern of gut-joint axis pathology is evidenced in Whipple disease and jejunoileal bypass arthritis ${ }^{10,11}$. Intriguingly, over $50 \%$ of patients with $\mathrm{SpA}$ and PsA have subclinical gut inflammation, supporting the involvement of mucosal inflammation in the pathogenesis of these diseases ${ }^{12,13}$.

Similarly, there is an intimate and reciprocal connection between gut and joint inflammation in inflammatory bowel disease (IBD), in which peripheral arthritis occurs in up to $25 \%$ of patients ${ }^{14}$. Spine involvement, particularly asymptomatic sacroiliitis, is even more frequent, with fully manifested AS developing in up to 1 in 10 patients with IBD.

Animal models of SpA and PsA (i.e., HLA-B27 transgenic rats and SKG mice) do not develop SpA-like disease when raised under germ-free conditions (cages voided of microorganisms). It is only when exposed to specific members of the enteric community that these animals develop the phenotype (peripheral arthritis, SpA, psoriasiform skin disease, and Crohn-like ileitis), supporting the hypothesis that gut microbiota is indeed necessary for the initiation of disease ${ }^{15,16}$. However, the mechanism by which this occurs is still a matter of intense research. Certainly, the role of Type-17 cells and the interleukin (IL)-23/IL-17 axis appears to play a central role ${ }^{17,18,19}$ because these cells are essential in the initiation and maintenance of gut inflammation in
$\mathrm{IBD}^{20}$. Similarly, the high expression of IL-17 can be found in the synovial fluids of $\mathrm{SpA}$, while increased circulating Th17 cells have also been reported ${ }^{21}$.

To date, there have been few comprehensive studies of intestinal inflammation characterization in humans with SpA spectrum disease and PsA. Classic work by Mielants, et al initially found an increased intestinal permeability in patients with RA, SpA, and $\mathrm{IBD}^{22}$. More recent, Ciccia, et al found that more than half of patients with PsA have subclinical gut inflammation and increased levels of Th17 as well as Th9 cells ${ }^{23}$. Similarly, only a handful of studies have characterized the link between PsA and the microbiome. Two studies have assessed the cutaneous microbiota composition in patients with psoriasis, with somehow divergent findings. However, both Gao, et al and Fahlén, et al found that psoriatic plaques have a significantly lower abundance of Propionibacterium spp. ${ }^{24,25}$. This is of interest because PsA develops in up to one-third of patients with psoriasis, making the skin microbiome a potential biomarker (and target) for the development of synovio-entheseal inflammation.

Our group described the intestinal microbiome in both patients with psoriasis and PsA compared to healthy controls and found that, while both psoriasis and PsA groups showed decreased abundance of the Coprococcus genus compared to healthy controls, the PsA group was further characterized by significantly lower levels of the Akkermansia and Ruminococcus genera. This suggests a continuum in the loss of diversity that may potentially correlate with the natural history of disease ${ }^{26}$. Curiously, studies in IBD also implicate these genera, with a decreased abundance of Ruminococcus and Akkermansia in both ulcerative colitis and Crohn disease ${ }^{27}$. Further, we found that this intestinal dysbiosis in patients with PsA correlates with decreased levels of medium-chain fatty acids (MCFA) in the intestinal luminal content, which are known to be beneficial for the maintenance of gut epithelial health ${ }^{28}$. These may also represent potentially modifiable biological factors in the progression from psoriasis to $\mathrm{PsA}^{26}$. Although this is still a nascent field, recent work on human $\mathrm{SpA}^{29}, \mathrm{IBD}-\operatorname{arthritis}^{30}$, and $\mathrm{ReA}^{31}$ points toward a common gut dysbiotic process that underlies these inflammatory arthritides.

\section{Strategies to Restore Intestinal Homeostasis}

There are multiple potential ways to alter the intestinal microbial community in an attempt to restore gut health and downstream immune responses in psoriatic disease. The strategies range from dietary habit changes to modifying the bioactive molecules that are produced by bacterial strains. Although there is some evidence for a potential clinical benefit of weight loss in psoriasis and $\mathrm{PsA}^{32,33}$, the data remain nonexistent for microbial ecosystem therapeutics through fecal microbiota transplant. This is not the case in IBD, where many studies have shown significant positive results in the treatment of colitis ${ }^{34,35,36}$, supporting an

Personal non-commercial use only. The Journal of Rheumatology Copyright @ 2018 . All rights reserved. 
argument that these interventions could at least theoretically be applied to the treatment of psoriatic disease.

The involvement of the microbiome in humans has been studied for several decades and is familiar to the rheumatology community. The advent of large, parallel sequencing technologies and dramatic advances in the understanding of mucosal immunology have provided a more precise knowledge of the microbe-host cross-talk in physiology and inflammatory disease. How and why microorganisms and their components influence immune homeostasis and the downstream activation of proinflammatory events in autoimmunity is a matter of intense research. Similarly, the application of this basic knowledge in the clinical setting and as potential therapeutic targets is offering new opportunities for the treatment and prevention of psoriatic disease and related conditions.

\section{REFERENCES}

1. Lederberg J. Infectious history. Science 2000;288:287-93.

2. Ley RE, Lozupone CA, Hamady M, Knight R, Gordon JI. Worlds within worlds: evolution of the vertebrate gut microbiota. Nat Rev Microbiol 2008;6:776-88.

3. Human Microbiome Jumpstart Reference Strains Consortium, Nelson KE, Weinstock GM, Highlander SK, Worley KC, Creasy $\mathrm{HH}$, Wortman JR, et al. A catalog of reference genomes from the human microbiome. Science 2010;328:994-9.

4. Dominguez-Bello MG, Costello EK, Contreras M, Magris M, Hidalgo G, Fierer N, et al. Delivery mode shapes the acquisition and structure of the initial microbiota across multiple body habitats in newborns. Proc Natl Acad Sci U S A 2010;107:11971-5.

5. Yeoh N, Burton JP, Suppiah P, Reid G, Stebbings S. The role of the microbiome in rheumatic diseases. Curr Rheumatol Rep 2013;15:314

6. Koenig JE, Spor A, Scalfone N, Fricker AD, Stombaugh J, Knight R, et al. Succession of microbial consortia in the developing infant gut microbiome. Proc Natl Acad Sci U S A 2011;108 Suppl 1:4578-85.

7. Scher JU, Littman DR, Abramson SB. Microbiome in inflammatory arthritis and human rheumatic diseases. Arthritis Rheumatol 2016;68:35-45

8. Honda K, Littman DR. The microbiome in infectious disease and inflammation. Annu Rev Immunol 2012;30:759-95.

9. Carter JD, Hudson AP. Reactive arthritis: clinical aspects and medical management. Rheum Dis Clin North Am 2009;35:21-44.

10. Moos V, Schneider T. Changing paradigms in Whipple's disease and infection with Tropheryma whipplei. Eur J Clin Microbiol Infect Dis 2011;30:1151-8.

11. Ross CB, Scott HW, Pincus T. Jejunoileal bypass arthritis. Baillieres Clin Rheumatol 1989;3:339-55.

12. Mielants H, Veys EM, De Vos M, Cuvelier C, Goemaere S, De Clercq L, et al. The evolution of spondyloarthropathies in relation to gut histology. I. Clinical aspects. J Rheumatol 1995;22:2266-72.

13. Manasson J, Scher JU. Spondyloarthritis and the microbiome: new insights from an ancient hypothesis. Curr Rheumatol Rep 2015;17:10.

14. Arvikar SL, Fisher MC. Inflammatory bowel disease associated arthropathy. Curr Rev Musculoskelet Med 2011;4:123-31.

15. Rath HC, Herfarth HH, Ikeda JS, Grenther WB, Hamm TE Jr, Balish E, et al. Normal luminal bacteria, especially Bacteroides species, mediate chronic colitis, gastritis, and arthritis in HLA-B27/human beta2 microglobulin transgenic rats. J Clin Invest 1996;98:945-53.
16. Hammer RE, Maika SD, Richardson JA, Tang JP, Taurog JD Spontaneous inflammatory disease in transgenic rats expressing HLA-B27 and human beta $2 \mathrm{~m}$ : an animal model of HLA-B27-associated human disorders. Cell 1990;63:1099-112.

17. Yoshitomi H, Sakaguchi N, Kobayashi K, Brown GD, Tagami T, Sakihama T, et al. A role for fungal \{beta\}-glucans and their receptor Dectin-1 in the induction of autoimmune arthritis in genetically susceptible mice. J Exp Med 2005;201:949-60.

18. Benham H, Rehaume LM, Hasnain SZ, Velasco J, Baillet AC, Ruutu $\mathrm{M}$, et al. Interleukin-23 mediates the intestinal response to microbial $\beta$-1,3-glucan and the development of spondyloarthritis pathology in SKG mice. Arthritis Rheumatol 2014;66:1755-67.

19. Rehaume LM, Mondot S, Aguirre de Carcer D, Velasco J, Benham $\mathrm{H}$, Hasnain SZ, et al. ZAP-70 genotype disrupts the relationship between microbiota and host, leading to spondyloarthritis and ileitis in SKG mice. Arthritis Rheumatol 2014;66:2780-92.

20. Seiderer J, Elben I, Diegelmann J, Glas J, Stallhofer J, Tillack C, et al. Role of the novel Th17 cytokine IL-17F in inflammatory bowel disease (IBD): upregulated colonic IL-17F expression in active Crohn's disease and analysis of the IL17F p.His161Arg polymorphism in IBD. Inflamm Bowel Dis 2008;14:437-45.

21. Appel H, Maier R, Wu P, Scheer R, Hempfing A, Kayser R, et al. Analysis of IL-17(+) cells in facet joints of patients with spondyloarthritis suggests that the innate immune pathway might be of greater relevance than the Th17-mediated adaptive immune response. Arthritis Res Ther 2011;13:R95.

22. Mielants H, Veys EM, De Vos M, Cuvelier C. Increased intestinal permeability in ankylosing spondylitis. Gut 1992;33:1150.

23. Ciccia F, Guggino G, Ferrante A, Raimondo S, Bignone R, Rodolico $\mathrm{V}$, et al. Interleukin-9 overexpression and Th9 polarization characterize the inflamed gut, the synovial tissue, and the peripheral blood of patients with psoriatic arthritis. Arthritis Rheumatol 2016;68:1922-31.

24. Gao Z, Tseng CH, Strober BE, Pei Z, Blaser MJ. Substantial alterations of the cutaneous bacterial biota in psoriatic lesions. PLoS One 2008;3:e2719.

25. Fahlén A, Engstrand L, Baker BS, Powles A, Fry L. Comparison of bacterial microbiota in skin biopsies from normal and psoriatic skin. Arch Dermatol Res 2012;304:15-22.

26. Scher JU, Ubeda C, Artacho A, Attur M, Isaac S, Reddy SM, et al. Decreased bacterial diversity characterizes the altered gut microbiota in patients with psoriatic arthritis, resembling dysbiosis in inflammatory bowel disease. Arthritis Rheumatol 2015;67:128-39.

27. Png CW, Linden SK, Gilshenan KS, Zoetendal EG, McSweeney CS, Sly LI, et al. Mucolytic bacteria with increased prevalence in IBD mucosa augment in vitro utilization of mucin by other bacteria. Am J Gastroenterol 2010;105:2420-8.

28. Anbazhagan AN, Priyamvada S, Gujral T, Bhattacharyya S, Alrefai WA, Dudeja PK, et al. A novel anti-inflammatory role of GPR120 in intestinal epithelial cells. Am J Physiol Cell Physiol 2016;310:C612-21.

29. Tito RY, Cypers H, Joossens M, Varkas G, Van Praet L, Glorieus E, et al. Brief report: dialister as a microbial marker of disease activity in spondyloarthritis. Arthritis Rheumatol 2017;69:114-21.

30. Viladomiu M, Kivolowitz C, Abdulhamid A, Dogan B, Victorio D, Castellanos JG, et al. IgA-coated E. coli enriched in Crohn's disease spondyloarthritis promote TH17-dependent inflammation. Sci Transl Med 2017;9(376).

31. Manasson J, Shen N, Garcia Ferrer HR, Ubeda C, Iraheta I, Heguy $\mathrm{A}$, et al. Gut microbiota perturbations in reactive arthritis and postinfectious spondyloarthritis. Arthritis Rheumatol 2018;70:242-54.

32. Eder L, Thavaneswaran A, Chandran V, Cook RJ, Gladman DD. Obesity is associated with a lower probability of achieving sustained minimal disease activity state among patients with psoriatic arthritis. Ann Rheum Dis 2015;74:813-7. 
33. di Minno MN, Peluso R, Iervolino S, Lupoli R, Russolillo A, Scarpa $\mathrm{R}$, et al. Obesity and the prediction of minimal disease activity: a prospective study in psoriatic arthritis. Arthritis Care Res 2013;65:141-7.

34. Borody TJ, Warren EF, Leis S, Surace R, Ashman O. Treatment of ulcerative colitis using fecal bacteriotherapy. J Clin Gastroenterol 2003;37:42-7.
35. Kelly CR, Khoruts A, Staley C, Sadowsky MJ, Abd M, Alani M, et al. Effect of fecal microbiota transplantation on recurrence in multiply recurrent Clostridium difficile infection: a randomized trial. Ann Intern Med 2016;165:609-16.

36. Moayyedi P, Surette MG, Kim PT, Libertucci J, Wolfe M, Onischi $\mathrm{C}$, et al. Fecal microbiota transplantation induces remission in patients with active ulcerative colitis in a randomized controlled trial. Gastroenterology 2015;149:102-9.e6. 